\title{
QUALIDADE NO ATENDIMENTO: FATOR FUNDAMENTAL NA MANUTENÇÃO DOS CLIENTES
}

Dennis Wilkerson Santos Zanelotti, Lucas de Souza Cardoso, Rogerio Alves Pereira, Thais Rubia Ferreira Lepre

Universidade do Oeste Paulista - UNOESTE, TCS Gestão Comercial, Presidente Prudente, SP. E-mail: thaisrubia@unoeste.br

\section{RESUMO}

A alta concorrência no mercado somada a consumidores cada vez mais informados, rígidos e criteriosos em suas escolhas de compra, traz nova demandas as organizações, entre elas, a principal é manter os clientes, e para tanto é necessário atraí-los e fidelizá-los, e isso pode ser obtido de formas diferentes, destacando-se o atendimento de qualidade. Tendo em vista que este é o fator mais citado entre os consumidores para justificar o porquê que não compram mais em determinada empresa. Justificando a existência deste estudo, que visa discutir tal questão, beneficiando com informação, a todos os gestores, que enxergarão a diferença que o bom atendimento pode fazer nos seus negócios, tendo em vista que, este artigo tem como objetivo demonstrar a qualidade no atendimento: fator fundamental na manutenção dos clientes. $E$ para tanto, contou com uma abordagem qualitativa, tendo a pesquisa bibliográfica como instrumento de coleta de dados. E foi possível concluir que, atendimento de qualidade é essencial para sobrevivência de qualquer negócio no mercado.

Palavras-chave: Qualidade. Atendimento. Organizações. Clientes.

\section{QUALITY IN THE SERVICE: FUNDAMENTAL FACTOR IN CUSTOMER MAINTENANCE}

\section{ABSTRACT}

The high competition in the market, together with consumers who are increasingly informed, rigid and judicious in their purchasing choices, brings new demands to organizations, among them, the main one is to keep customers, and for that, it is necessary to attract and retain them, and this can be achieved in different ways, with emphasis on quality care. Given that this is the most cited factor among consumers to justify why they do not buy more in a certain company. Justifying the existence of this study, which aims to discuss this issue, benefiting with information, all managers, who will see the difference that good service can make in their business, considering that, this article aims to demonstrate the quality of care : fundamental factor in the maintenance of customers. And for that, it counted on a qualitative approach, having the bibliographical research as instrument of data collection. And it was possible to conclude that, quality service is essential for the survival of any business in the market.

Keywords: Quality. Attendance. Organizations. Client.

\section{INTRODUÇÃO}

A abertura do mercado brasileiro na década de 90 trouxe novos desafios às organizações, considerando que a concorrência tornou-se mais acirrada devido à facilitação de importação, que trouxe novos produtos ao mercado, e possibilitou a utilização de matérias-primas importadas, com custo menor, elevando a necessidade das empresas de buscar diferenciais. Somado a isso, já nos anos 2000, a internet começou a popularizar-se nos lares brasileiros, oferendo a facilidade de 
realizar compras on-line de empresas do mundo todo, aumentando ainda mais o desafio das organizações, na busca pela manutenção de clientes.

Atualmente, esse mercado encontra-se cada vez mais competitivo, com disputa de preços e formas de entregas, pagamentos, onde os clientes têm varias opções e disponibilidade de serviços e produtos a seu favor e com forma de escolher o que melhor $o$ atende.

Para que as organizações conquistem esses clientes e uma demanda maior no mercado é preciso investimento na qualidade do atendimento ao mesmo, garantindo que a fidelização e satisfação em relação à compra final.

De acordo com Neiva e D’Elia (2009, p. 133) “para as organizações que querem permanecer no mercado competitivo, a qualidade é uma questão de sobrevivência".

Justificando a existência deste artigo que visa discutir tal questão, beneficiando com informação, a todos os gestores, que enxergarão a diferença que o bom atendimento pode fazer nos seus negócios, tendo em vista que, este artigo tem como problemática: qual a importância da qualidade do atendimento na manutenção dos clientes?.

Esse estudo tem como objetivo de demonstrar a importância de uma empresa apresentar qualidade no atendimento a seus clientes, a modo de satisfazê-los e mantê-los fidelizados.

\section{METODOLOGIA}

Considerando que a metodologia utilizada para atingir o objetivo deve estar presente em qualquer trabalho de cunho científico, este artigo contou com uma abordagem qualitativa e uma pesquisa bibliográfica. Nos parágrafos seguintes tem-se a descrição destes métodos e de sua utilização neste estudo.

Iniciando pela abordagem qualitativa, segundo Mascarenhas (2012, p. 46):

Utilizamos a pesquisa qualitativa quando queremos descrever nosso objeto de estudo com mais profundidade. Por isso, ela é muito comum em estudos sobre o comportamento de um indivíduo ou de um grupo social. [...] Suas principais características são: os dados são levantados e analisados ao mesmo tempo; os estudos são descritivos, voltados para a compreensão do objeto; a influência do pesquisador sobre a pesquisa não é evitada; muito pelo contrario, é considerada fundamental.

Justificando sua escolha para este artigo, que busca descrever e interpretar as questões relacionadas à qualidade no atendimento, com a finalidade de explicar e não de mensurar, em que não se busca generalizações, mas o entendimento da situação especificamente.

Por isso o instrumento de coleta de dados utilizado foi à pesquisa bibliográfica. Para Gil (2010, p. 29), “a pesquisa bibliográfica é elaborada com base em material já publicado. Tradicionalmente, esta modalidade de pesquisa inclui material impresso, como livros, revistas, jornais, teses, dissertações e anais de eventos científicos". Materiais estes que serviram de base para alcance do objetivo proposto neste artigo.

\section{REFERENCIAL TEÓRICO}

Diferentemente de como acontecia há algumas décadas, atualmente os clientes tem a sua disposição uma diversidade de opções de locais (seja lojas físicas ou virtuais) para realizar suas compras, onde o número de empresas cada vez aumenta mais, fazendo com que o mercado fique cada vez mais competitivo e acirrado. Para os consumidores isso é ótimo, mas para as empresas é um grande desafio, pois:

A concorrência que as empresas hoje enfrentam é a mais acirrada de todos os tempos (...). Para vencer no mercado de hoje, eles precisam transformar-se em peritas não apenas na construção de produtos, mas 
também na construção de clientes, a solução está em executar o trabalho de entregar valor e satisfação para o cliente melhor do que os concorrentes.(KOTLER; ARMSTRONG, 2003, p.474).

Diante deste cenário, é preciso que as organizações invistam nos seus colaboradores, segundo Whiteley (1992, p. 87) as empresas necessitam "envolver os talentos das pessoas não somente nas suas tarefas normais para o cliente, mas também no constante processo da companhia. Por muito tempo, as companhias tenderam a contratar pessoas pela sua força muscular. Atualmente, precisamos também de sua força cerebral". Pois os clientes não esperam apenas um produto ou serviço de qualidade, eles buscam principalmente ser bem recebidos, receber atenção, isso é visto hoje como diferencial, e somente as pessoas podem dar um atendimento de qualidade, e para tanto, saber quem são os clientes da empresa é essencial.

"Conheça os seus clientes como sua própria família, satisfaça-os completamente, e você alcançará o sucesso [...] a chave é que todos na organização precisam calibrar suas ações conforme as necessidades, as expectativas e os desejos dos clientes" (WHITELEY, 1992, p.21).

Ou seja, é preciso analisar, estudar e saber quem são seus clientes, o que estão buscando e quais os objetivos que querem chegar ao adentrar em seu estabelecimento, para que assim a empresa atenda-o de forma eficiente e suprindo as necessidades e desejos o que o mesmo procura.

E como conseguir isso? Apresentando aos colaboradores que trabalham diretamente com as pessoas, quem são clientes e o que eles buscam, para que o atendimento seja assertivo e gere satisfação.

Atendimento de qualidade ao cliente não é apenas mostrar e vender aquilo que ele pede. É mais que isso, é compreendê-los, saber suas necessidades, suas expectativas, escutar o que ele tem a dizer, ter paciência, ou seja, fazê-lo sentir-se importante. Pois, a satisfação do cliente é fundamental para o sucesso da organização, e essa consciência em oferecer um bom atendimento é primordial para permanecer no mercado competitivo e cheio de concorrentes.

Como afirma Kotler (2000, p. 142):

Um cliente pode ter vários níveis de satisfação. Se o desempenho ficar abaixo dessa expectativa, o cliente ficará insatisfeito. Se o produto preencher as expectativas, ele ficará satisfeito. Se o produto exceder essas expectativas, o cliente ficará altamente satisfeito ou encantado.

A satisfação requer um grau de atenção e compreender a demanda e expectativa dos clientes, fazendo com que os objetivos internos da empresa se voltem exatamente para essa questão. Portanto, é importante avaliar constantemente o nível de satisfação, procurando agir tanto de forma preventiva para evitar erros.

Atendimento diferenciado no mercado competitivo é uma das formas de crescimento das vendas, produção e evolução da empresa, onde pode ser essencial para prestar um atendimento com qualidade, pois os clientes com suas expectativas atendidas podem retornar em diversas ocasiões, desfrutando dos serviços disponibilizados pela organização, sendo que, ao contrário, os clientes ficarão insatisfeitos e poderão repassar sua insatisfação para outras pessoas. Assim tendo um atendimento diferenciado e mostrando o melhor que sua empresa pode proporcionar ao cliente satisfação e bem - estar. Consideram-se também outras caraterísticas de um atendimento diferenciado. Segundo Svadon (apud ALMEIDA, 2001) é importante analisar cada cliente antes de prestar o atendimento, percebendo rapidamente qual seu perfil. Analisando suas características e seu tipo de personalidade.

É importante que esteja sempre atento à voz do cliente, prestando atenção no que está sendo solicitado, analisando o comportamento e atitude no momento do atendimento, comprometendo, resolvendo seus problemas e suprindo suas necessidades. 
A qualidade mostra ser um conjunto de valores agregados aos funcionários no atendimento aos seus clientes, o que se entende por diferencial no atendimento com qualidade. Precisa haver um esforço geral e abrangente de conscientização coletiva do serviço, das necessidades do cliente, da cooperação e do trabalho de equipe em nome da qualidade para que a empresa obtenha a fidelidade do cliente. E atualmente as organizações já perceberam a importância da fidelização, tendo em vista que o gasto para atração de clientes é alto, por isso, é preciso aproveitar a oportunidade de contato com o cliente para satisfazê-lo em busca da fidelização.

"Cliente fiel é aquele tem o comportamento em constantes realizações de compras regulares e repetidas, recomendando produtos e serviços a outras pessoas, não se sensibilizando com a estratégia da concorrência" (GRIFFIN 1998, p. 47).

O cliente realmente fiel vai rejeitar a concorrência, manter fiel a mesma empresa sempre que precisar do produto ou serviço. Para isso, há um caminho duro e demorado a ser seguido pela empresa, a fim de reter seus consumidores. A fidelidade é conquistada em longo prazo, através de atitudes, conhecimentos que transmitam confiança, respeito, cuidado, atenção, carinho e paciência, ou seja, através de um atendimento de qualidade.

\section{CONCLUSÃO}

Em um mundo de constantes mudanças, o sucesso ou fracasso de uma organização está diretamente ligado à capacidade de entender, atrair, satisfazer e encantar o cliente. A satisfação do cliente não se resume apenas nas necessidades supridas, ele espera sempre mais, quer ter suas expectativas atingidas, deseja sempre ser surpreendido. Ciente de que a satisfação não garante o retorno da clientela, é necessário desenvolver um relacionamento contínuo entre empresa e cliente, ou seja, oferecer-lhe o maior valor agregado às suas necessidades e expectativas, podendo diferenciar-se da concorrência na qualidade de atendimento. Assim, este estudo teve como objetivo demonstrar a importância da qualidade no atendimento para manutenção dos clientes nas empresas.

Diante de todo desenvolvimento do conteúdo no decorrer deste trabalho, foi possível concluir que a qualidade no atendimento é uma ferramenta essencial na execução das tarefas realizadas dentro de qualquer empresa. As organizações possuem uma enorme capacidade de adaptarem-se a mudanças do mercado e às necessidades dos clientes, demonstrando um grande potencial no desenvolvimento da orientação para o cliente, conquistando um diferencial competitivo em relação às outras organizações.

A realização deste trabalho possibilitou a ampliação do conhecimento sobre o assunto, pois agora se sabe ainda mais da relevância que o atendimento pode proporcionar dentro da empresa Pode-se dizer que satisfazer o cliente está ligado a todos os setores da empresa, desde a alta administração até o nível operacional, já que todos são peças fundamentais neste processo de satisfação. Vale ressaltar que os clientes são parceiros indispensáveis para o sucesso da organização e que devem ser ouvidos e atendidos com atenção, respeito e confiança que merecem.

\section{REFERÊNCIAS BIBLIOGRÁFICAS}

ALMEIDA, S. Ah! Eu não acredito: como cativar o associado através de um fantástico atendimento. Salvador: Casa da qualidade. 2001,p 75.

FREEMANTLE, D. Incrível atendimento ao cliente. São Paulo: Makron Books, 2001.

GIL, A. C. Como Elaborar Projetos de Pesquisa. 5. ed. São Paulo: Atlas, 2010. 
GRIFFIN,J. Como conquistar e manter o cliente fiel: Transformar seus clientes em verdadeiros parceiros. São Paulo: Fatura, 1998.

JUAIS, J. C. Satisfação dos Clientes. Disponível em: <http://www.administradores.com.br/artigos/ marketing/satisfacao-dos-clientes-gera-lucros-para-a-empresa/30055/>. Acesso em: 15 out. 2016.

KOTLER, P.; ARMSTRONG, G. Princípios de Marketing. 9. ed.São Paulo: Prentice Hall, 2003.

KOTLER, P. Administração de marketing: a edição do novo milênio. São Paulo: Prentice Hall, $2000, p 142$.

MASCARENHAS, S. A. Metodologia Científica. São Paulo: Pearson Education do Brasil, 2012.

NEIVA, Edméa Garcia; D’ELIA, Maria Elizabete Silva. As novas competências do profissional de secretariado. 2. ed. São Paulo: IOB, 2009, p 133

POSTIGO, I. Cliente interno, fonte de lucros ou prejuízos. Disponível em: <http://www.artigos.com/artigos/10576-cliente-interno-fonte-de-lucros-ou-prejuizos>. Acesso em: 15 out. 2016.

QUALIDADE NO ATENDIMENTO COMO FATOR DE CRESCIMENTO EMPRESARIAL. Revista de Iniciação Científica - RIC Cairu. Jun. 2015, Vol 02, p.112-113, ISSN 2258-1166.

RIBEIRO, H. M. Diferencia e Qualidade no Atendimento. Disponível em: <http://www.administradores.com.br/artigos/marketing/qualidade-de-atendimento-e-asatisfacao-dos-clientes-da-etitec-automacao/24371/>. Acesso em: 17 ago. 2016.

SARTI, T.Ambiente de Trabalho. Disponível em: <http://www.artigos.com/artigos/5412ambiente-de-trabalho-e-satisfacao-do-cliente>. Acesso em: 15 out. 2016.

TITO, D. Atendimento e Eficiencia. Disponível em: <http://www.voxage.com.br/a-consultoriacom-foco-na-eficiencia-do-atendimento-pode-ser-um-diferencial-competitivo-para-o-seunegocio/>. Acesso em: 18 set. 2016.

WHITELEY, R. A empresa totalmente voltada para o cliente. 14.ed. Rio de Janeiro: Campos, 1992. 